\title{
Evaluating EFL University Learners' Pragmatic Competence: Brown and Levinson's Negative Politeness Strategies as a Model
}

\author{
Ali Yousif Mohammad ${ }^{1}$, Hussein Ali Ahmed Allo ${ }^{2}$ \\ ${ }^{1}$ Department of English, College of Arts, University of Mosul, Iraq \\ 2 Department of English, Nawroz University, Kurdistan Region-Iraq
}

\begin{abstract}
Pragmatic competence forms a basic pillar in learning and teaching the communicative use of a foreign language. Evaluating the FL pragmatic knowledge is a challenging and complex area of language testing. Far from the grammatical content of language, the current study aims to evaluate English as a foreign language learners' pragmatic competence in terms of communicating the linguistic expressions of negative politeness. Accordingly, it investigates English as a foreign language university students' ability to show social distance and realize power relations towards addressees. The study also presents the negative politeness strategies on the basis of Brown and Levinson's (1987) theory.
\end{abstract}

It is hypothesized that learners are pragmatically unaware of showing a negative face towards addressees. It is further assumed that learners show a tendency to go on record without a redressive action, which often threatens addressees' negative face. Added to that, learners are not aware of the appropriate use of politeness strategies followed according to the English culture. To investigate this, a Discourse Completion Test consisting of hypothetical situations that are familiar to learners' university life has been formulated.

The study concludes that learners experience pragmatic failures while engaging in situations where there is a need to show a negative face, and utter direct speech acts frequently. In addition, learners do not distinguish between the appropriate politeness strategies (positive, negative and off record) as far as the cultural orientation of the English language is concerned. They further disregard the appropriate use of address forms that constitute a paramount aspect of negative politeness.

\section{The Theoretical Part}

\subsection{Introduction}

Social interaction depends on language not just as a means for communicating information, but also for establishing rapport between interlocutors. In fact, each speech community develops and adopts its own conventions and rules for the linguistic expressions of politeness. In terms of politeness, effective and successful communication entails applying pragmatic competence (PC) in relation to both 'positive' and 'negative' politeness. The former is performed by reducing social distance (SD) so as to appear sociable and friendly, whereas the latter is expressed by showing autonomy towards the hearer $(\mathrm{H})$.

Consequently, the speaker (S) in making appropriate

\footnotetext{
i A speech community refers to a group of people who employ the same set of speech signals .Van Herk (2012:211) describes it as a group of people whose interaction is performed by means of speech. They are in a habitual contact with each other and share a variety of language and social conventions about the use of
}

language. Interpersonal relationships with the $\mathrm{H}$. Thus, Holmes (2013:274) states that linguistic politeness stems from the selection of linguistic forms represented by illocutionary competence (IC) which are perceived as expressing an appropriate degree of $\mathrm{SD}$, and acknowledge relevant status and power relations (PRs) represented by socio- linguistic competence (SC). Then, if the inappropriate strategy is chosen, $\mathrm{S}$ might give the impression of being impolite, rude and impulsive towards the $\mathrm{H}$.

\subsection{The Problem of the Research}

Concerning the problem of the research, in formal and distant situations, socially inappropriate language behaviour forms a real threat to the H's face as $\mathrm{s} /$ he might hazard being mortified or embarrassed. With regard to EFL learners, owing to their lack of linguistic competence (LC) and consequently communicative competence (CC), they show no awareness of distance and autonomy, viz. the socio-cultural knowledge of the language, 
towards the H's negative face when engaged in formal interactions. In other words, most English as foreign language learners noticeably misuse the social rules and the cultural norms of the target language in formal interactions.

\subsection{The Hypotheses}

Accordingly, it is hypothesized that

- English as foreign language fourth-year university students do not attend to the hearer's negative face (in terms of showing social SD, realizing Rs and understanding the rank of imposition $(\mathrm{Rx})$ they make,

- English as foreign language fourth-year university students tend to go on record without redressive linguistic action in distant situations, and

- English as foreign language fourth-year university students do not recognize the appropriate uses of politeness strategies as far as the cultural orientation of English is concerned.

\subsection{The Aims of the Research}

The current research aims to evaluate English as a foreign language learners' pragmatic competence in terms of communicating the linguistic expressions of negative politeness. It further investigates English as a foreign language university students' ability to show social distance and realize power relations towards addressees. Finally, this research aims at presenting the negative politeness strategies on the basis of Brown and Levinson's (1987) theory.

\subsection{Pragmatic Competence}

Pragmatics, as a branch of linguistics, is defined by Crystal (2008: 364) as "the study of language from the point of view of users, especially of the choices they make, the constraints they encounter in using language in social interaction and the effects their use of language has on other participants in the act of communication". The importance of the role played by pragmatics in CC framework has led to increased attention paid to PC. It is well noted, however, that this term has begun to spread widely in the context of teaching and learning English, in particular, to language assessment and evaluation. Bachman (1990:89-90) and Bachman and Palmer (2010:45) state that PC embraces two-sided knowledge, name the relationship between referents and the social context on the other hand. Here, familiarity with the pragmatic conventions is required so as to put both acceptable language functions and the knowledge of the sociolinguistic conventions into practice for the sake of the appropriate use of language.

It is significant to state that PC comprises IC and SC. Canale (1988) confirms that the pragmatic component of CC implicitly includes illocutionary knowledge and socio-linguistic conventions. Thus, he defines PC as the relationship between utterances and the acts or functions intended behind the performance of such utterances. This is called the illocutionary force of utterance. Additionally, pragmatic competence comprises illocutionary competence, i.e. awareness of the pragmatic convention for acceptable language functions performance, and sociolinguistic competence, i.e. knowledge of sociolinguistic conventions for appropriate language function performance in a certain context.

Succinctly speaking, PC is viewed as comprising two aspects of communicative language use, viz. IC and SC; both of which complete one another and thus leads to the appropriate language use within the social context.

\subsection{Illocutionary Competence (IC)}

IC refers to the knowledge of the pragmatic conventions for acceptable language use, which holds a relationship between signs and users. It outlines the expression of language within certain illocutionary force and the interpretation of the illocutionary force of language (Bachman, 1990:91). Kasper and BlumKulka (1993:4) define IC as the capability of using language to utter a variety of communicative 
functions such as making reference. For example, the utterance "It is cold in here" may function as an assertion, warning or request to turn the heater on. EFL learners with IC can link the expressions they utter with the ideas and intentions that they want to share or interpret.

Bachman (1990) mentions four language functions of IC, namely ideational (the way meanings and experiences are conveyed); manipulative (language is instrumentally used to achieve ends; heuristic (language is used to talk about new things about our world and solving and imaginative (the use of language behind "here and there". It is worth noting that IC is equivalent to Leech's conception of pragmalinguistics which deals with the linguistic realization of language. However, whereas grammatical competence is described in relation to word and sentence level, Bachman (ibid: 90) describes IC in relation to Speech Acts (SAs), i.e. the functional use of language.

\subsection{Sociolinguistic Competence}

$\mathrm{SC}$ is related to IC in that it performs its force in such a manner that is conducive to the social context (Peterwagner, 2005:18). To elaborate on this, Bachman (1990: 90) states:

Imagine a context in which I wish to get someone to leave. To accomplish this, I use my illocutionary competence, which indicates that a simple statement can function as a request. I will also use my sociolinguistic competence ... to determine which of several possible statements is the most appropriate in this specific context.

According to Van Herk (2012:120) and Holmes (2013:440), SC is viewed as the knowledge which underlies the individuals' capacity to use language appropriately and communicatively in various sociocultural situations. Language proficiency, however, is observed alongside two dimensions, viz. accuracy and appropriateness. Unlike accuracy which is studied far from culture and context, appropriateness is unquestionably context-specific and culturebound. Effective communication in different sociolinguistic contexts occurs when language learners own competence comprising what interlocutors expected of the target language both socially and culturally.

\subsection{Politeness and Culture}

Being polite is deemed one important sign of human culture. In terms of human civilization, politeness is seen as a criterion of civility where a certain type and level of culture is reflected by the "appropriate" command of politeness. Hence, politeness can be a mean of to distinguishing one individual from another (Haugh and Kadar, 2013: 231). Each culture has a different perception of what is polite and it develops devices, formulas and strategies for expressing politeness. On that basis, some situations call for more politeness than others by depending on such factors as age, gender, distance, power, etc.. In fact, ways of speaking are determined by culture. On this basis, the means to reflect cultural values are developed by language.

Initially, a distinction should be drawn between two sorts of culture. There are cultures that give priority to the individual over the group, and collectivist cultures that show just the opposite. In addition, there is no clear demarcation between the two cultures, but there is rather a continuum between them (Culpeper and Demmen, 2009:50). However, it is stressed by many researchers that face wants are culture-specific; each language follows certain rules according to cultural norms and references. From a cross-cultural perspective, English speaking cultures give more weight to the autonomy of the individual compared to what many other cultures do (Leech, 2014:14). As such, it is a fact that the Anglo-Saxon cultural tradition respects the individual's rights, privacy and autonomy. Meanwhile, it detests interference and dogmatism in people's affairs. This means that negative politeness (formal politeness) is 
to a great extent taken for granted in such cultures. Brown and Levinson (1987: 30) argue that "when we think of politeness in the western culture, it is negative politeness behavior that springs to mind. In our culture, negative politeness is the most elaborate and the conventionalized set of linguistic categories for FTA redress". Accordingly, it is understood that English speech communities are ones in which relatively high value is placed on SD and accordingly negative politeness will prevail in social encounters and regulate the English communicative behaviour. On his part, Yule (1996: 78) emphasizes this by indicating that negative politeness is used to perform SAs in most English-speaking contexts.

Historically speaking, Jucker (2008:8) and Sifianou (1999: 35) report that in the British culture, negative politeness is that of the public sphere. It is hypothesized that there has been some sort of shift from positive politeness culture in the early modern Britain to present day negative politeness culture. Leech (1983:73), on his part, confirms that 'tact maxim', which is similar to negative politeness in a way or another, is the most prevalent and important type of politeness in the English-speaking societies. To validate this, Fox (2004: 173) views English culture as

$$
\begin{aligned}
& \text { "the identification of England as predominately } \\
& \text { negative politeness culture-concerned mainly with } \\
& \text { the avoidance of imposition and intrusion-seems to } \\
& \text { me quite helpful. The important point here is that } \\
& \text { politeness and courtesy, as practiced by the English, } \\
& \text { have very little to do with friendship or good } \\
& \text { nature". }
\end{aligned}
$$

To conclude, in the Western cultures, polite people tend to avoid being forceful, direct, and interruptive. The English cultures approach difference, formality and autonomy of individuals. Such cultures stress individualism and exclude collectivism which supports face social group and the total social traditions and customs.

\subsection{Face-Threatening Act Strategies}

Brown and Levinson (1987:69) propose four superstrategies to perform FTAs that are placed in five categories that $S$ chooses when performing FTAs, namely bald-on-record (with no redress), bald on record (with redress) with its two subdivisions: positive politeness and negative politeness, offrecord, and not performing FTAs (See Figure 1). These strategies show at which level $S$ tends to be polite and help communicators save each other's face wants so that one would behave in a strategic way to choose the appropriate strategy that fits the social context.

\subsection{Negative Politeness Strategies}

Negative politeness strategies acknowledge the hearer's autonomy, freedom of thought and selfprotection. They result in the acceptance of responsibility (Ogiermann, 2009:335). Accordingly, negative politeness can be defined as considerations for the hearer's wish to be unimpeded in taking action and having attention. Brown and Levinson (1987:70) state that in using such strategies, the want to go on record and off record simultaneously to avoid imposing leads to natural tension on the part of the Sr. Furthermore, Leech (2014:12) stresses the importance of negative politeness compared to positive politeness for the reason that "failure to show the former is likely to give the other person a sense of offence". This leads to social disharmony between interlocutors. Holmes (1995:20) states that negative strategies are recommended in situations where the a social distance exists between the $S$ and the $H$ and power relations record differences as well. Therefore, it is preferred that they are employed in formal interactions.

Finally, performing FTAs on record using negative politeness involves using strategies designed to reduce threats towards the $\mathrm{H}^{\prime}$ s negative face (see Figure 3). For the $S$ to put a social brake on his/her interaction course, Brown and Levinson 
suggest the following five high-strategies with their subcategories: Be direct, do not assume/presume, do not coerce the $\mathrm{H}$, communicate the S's want not to impinge on the $\mathrm{H}$ and redress other wants of the $\mathrm{H}$.

\subsubsection{Be Direct}

According to Brown and Levinson (1987: 130-172), the "be direct" super-strategy stems from on-record performance, viz. the want to say a message directly,

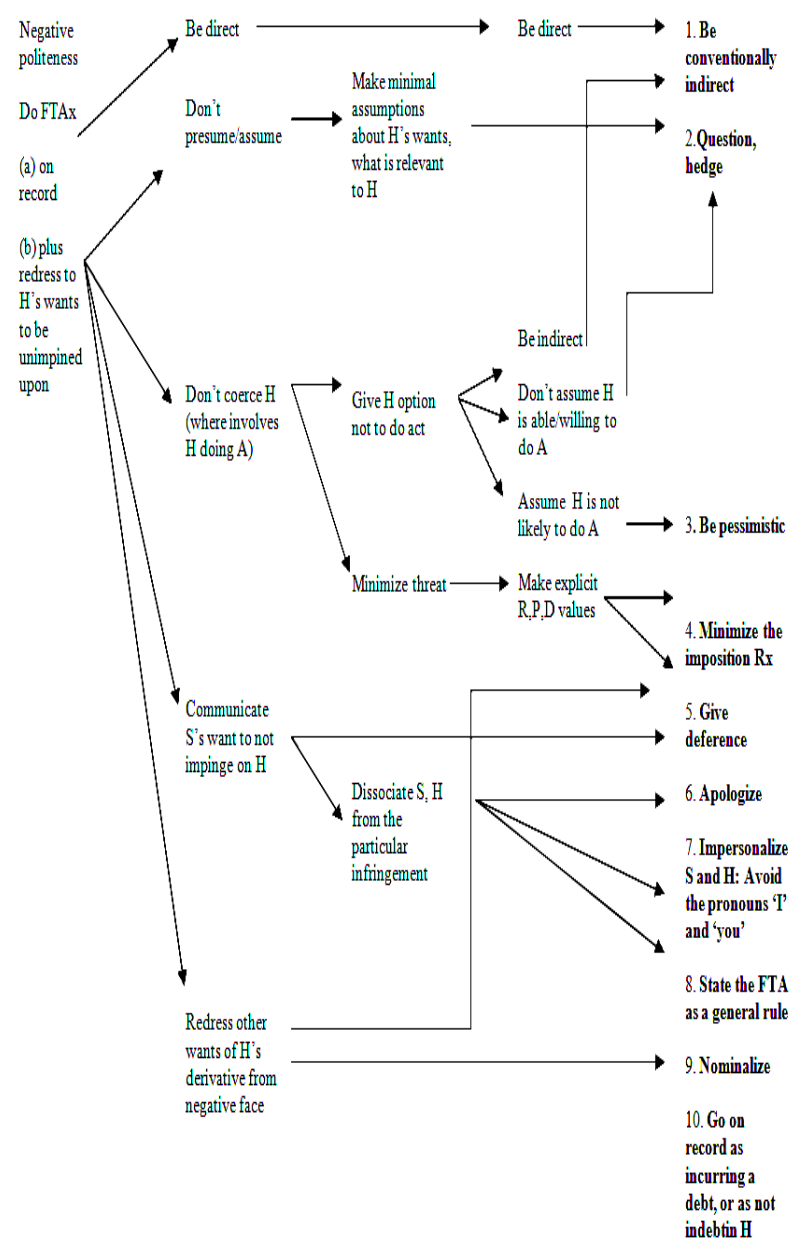

Figure (1): Negative Politeness Strategies (Brown and Levinson, 1987:131)

and the redress of FTAs for being plain. This kind of struggle is solved via conventional indirectness.

This entails to Be Conventionally Indirect since indirect SAs are harder to interpret and therefore the $S$ develops conventional indirect patterns that enable $\mathrm{H}$ to formulate acts that are unambiguous and clear. Conventional indirectness encodes the clash of wants; the want to go on record by requisitive force and the want to avoid appearing coercive. That is to say, the $S$ is allowed to be simultaneously direct and to have a desire not to be coerced). It is basically performed by questioning SAs, i.e. indirect SAs serve as ideal to do this hybrid function. Accordingly, the $S$ shows that $\mathrm{s} /$ he questions the ability or the willingness to perform SAs and thus not taking the H's compliance for granted. The result is that the $S$ says what $\mathrm{s} /$ he means but politely.

\subsubsection{Do not Presume/Assume}

One way of giving redress to the $\mathrm{H}$ is by "carefully avoiding presuming or assuming that anything involved in the FTAs is desired and believed by the $H^{\prime \prime}($ p.144). Hence, minimal assumptions of the H's wants and what is relevant to him/her are made by the $S$ makes in such a way that makes the $S$ questions and/or hedges such assumptions.

Hedges are politeness devices that are used to alleviate the force of SAs. As such they play a crucial role in the shaping of polite interaction. A hedge is " a particle, word or phrase that modifies the degree of membership of a predicate or noun phrase in a set; it says of that membership that it is partial or true only in certain respects, or that is more true and complete than perhaps might be expected." Examples are:

- It is a kind of cold here, is not it?

- Could we close the window?

- I think everyone knows they are unhappy (p.145).

\subsubsection{Do not Coerce the Hearer}

Based on Brown and Levinson (1987: 173-178), Some FTAs can be redressed by avoiding coercing the H's negative face. This super-strategy suggests the following three functions: $S$ 's assuming that the $\mathrm{H}$ is not willing to do SAs by giving an outlet to "run away"; minimizing the threat of coercion by clarifying that S's conceptualization of $\mathrm{Rx}$ is small and consequently coercion becomes small. The S's claim that the H's power is somewhat great implies the S's modesty towards the $\mathrm{H}$.

\section{Being Pessimistic}


Another strategy the $S$ can follow to protect the H's negative face is to be pessimistic. Accordingly, a redress is given to the $\mathrm{H}^{\prime}$ 's negative face by showing "an explicit doubt that the conditions of the appropriateness of S's SAs obtain"(p.173). To be pessimistic means assuming that the $\mathrm{H}$ is not likely to do the act. In other words, the $S$ does not expect a positive outcome from the H. Watts (2003:90) explains that being pessimistic shows the ability and the willingness not to comply on the part of the hearer.

The "being pessimistic" strategy can be realized in the following three forms:

- The use of negation plus a tag question located in the end of an act as in you couldn't help me, could you?

- The use of pessimistic subjunctive. Consider the following example:

Would you close the window rather than will you close the window?

- The use of remote-possibility markers as in:

I do not suppose that there is any chance that you are going to the store today. (p.175)

\section{Minimizing the Imposition}

Minimizing the imposition is performed by considering $\mathrm{Rx}$ is not itself great. In this way, SD and PRs are left as norms of weighty factors. In other words, it works on diminishing FTAs by showing that $\mathrm{Rx}$, the seriousness of the imposition, is low (p.176). Kopytko (1995:526) mentions a range of expressions that are used to minimize the size of imposition such as "little, a drop, a sip and just". An example is "Can I have a taste of that cake?" According to Brown and Levinson (ibid), minimizing the imposition can be mainly performed by "just", which does two functions. First, it is literally used in the sense of "exactly". Second, it has conventional implicature ${ }^{i i}$ in the sense "merely", which works on softening the force of FTAs. This can be illustrated by the following examples:

- I just want to ask you if I can borrow a little paper.

- Could I talk to you for just a minute? (Watts,
2003:90).

ii Conventional Implicature is an aspect of non-truth conditional meaning that arises because of the conventional features attached to a particular lexical item. Conventional implicature is not based on $\mathrm{CP}$ or the maxims, i.e. it does not depend on context for interpretation (Yule, 1996:45).

\section{Showing Difference}

With difference strategy the $S$ makes grammatical choices that are subject to the S's status, age, sex and social position. This strategy is then perceived as a sociolinguistic phenomenon whereby the $S$ is constrained to make choices from the grammatical system of language so as to communicate differently in a particular situation. Brown and Levinson (1987:178) point out that this strategy implies two dimensions. First, the $S$ humbles and degrades him/herself. Second, the S satisfies the H's wants, treating him/her as more superior. This can be exemplified by "I am ashamed to have to ask you this favor". This strategy appeals to authority; it gives the $\mathrm{H}$ increased power over the $S$, and is expected to "defuse potential face threatening acts by indicating that the addressees' rights".

\section{Communicating the Speaker's Wants Not to Impinge on the Hearer}

According to this strategy, and as Brown and Levinson (1987: 187-208) outline, the $S$ communicates that any infringement of the H's territory is recognized and is not undertaken lightly. This can be accomplished in four ways: SAs are impersonalized and generalized, the $S$ admits and apologizes for the imposition, FTAs are stated as general and nominalized.

\subsection{Impersonalizing the Speaker and the Hearer}

Impersonalization is formulated through wording "FTAs as if the agent were other than the $S$, or at least possibly not or notthe $S$ alone, and the addressee were other than the H or only inclusive of the H" (p.190). This strategy explains that an assumed character is suggested by the $S$ to take part on behalf of him/her. The $\mathrm{S}$ seemingly imposes less on the $\mathrm{H}$ by avoiding the pronouns "I" and "You". So the context of interaction becomes agentless and the $\mathrm{H}$ is not specified as the 
object of imposition.

Locher (2004:130) names this strategy "shifting responsibility" as it outlines a different source of an utterance. He argues that it is advantageous in an interaction as "the content of what the speaker just said might be debatable, but the person as such is not expected to criticisms as when s/he had reported the content as his/her own point of view"

Brown and Levinson (1987) suggest the following forms to impersonalize FTAs:

- Impersonal verbs in English: Verbs taking dative agents are often used with the agent deleted ( $\mathrm{p}$. 191). Consider the following example:

\section{- It appears to me that you look sad}

- Passivization and Circumstantial Voices: The S tries to reduce his/her presence where the doer of the act is defocused (p.194). Illustrative examples are:

- If it is possible (instead of) if you can

- Students are advised to write their assignments daily.

- Pronoun Replacing: The pronouns "I" and "you" are replaced by indefinites. Indefinites pronouns serve as a good softener in doing FTAs (p.197), as illustrated in the following example:

- One should not do things like that

instead of

- You should not do things like that.

- Viewpoint Distancing: It can be used to distance the $S$ from the $\mathrm{H}$ or from FTAs. This can be done by switching tense from present into past. In other words, the expression of tense is manipulated so as to provide distance in time (p.204). Consider the following example:

- I have been wondering whether you could do me a little favor.

\subsection{Apologizing}

The use of negative politeness strategies that address H's negative face needs includes apologizing before interacting. According to this strategy, "The $S$ shows his/her reluctance to impinge on the H's negative face and thereby partially redress that impingement"(p.187). Additionally, such reluctance is represented by hesitation and bumbliness that are impeded in SAs. Put differently, the $S$ makes an apology or qualification of prior utterances or behavior, where by doing so, the $S$ draws attention to the offence which might well have been overlooked otherwise.

This strategy suggests four forms that can be used to lighten the force of illocutionary acts before doing FTAs:

- Admitting the impingement: The S explicitly refers to the imposition caused to the $\mathrm{H}$ (ibid: 188). This is illustrated in the following example:

- I am sure that you must be very busy, but...

- Indicating reluctance: The $S$ endeavors show that $\mathrm{s} /$ he is reluctant to impose on the $\mathrm{H}$ with the use of hedges. Consider the following examples:

- I hate to impose, but.....

- I do not want to interrupt you, but...

- Giving overwhelming reasons: The $S$ claims that $\mathrm{s} /$ he has compelling reasons that indicate his/her inability for doing FTAs. An example is:

- I can think of nobody who could help me.

- I am absolutely lost could you .......

- Begging forgiveness: Begging forgiveness implies that the $\mathrm{H}$ should cancel the debt implicit in the FTA. That is, the $S$ asks for 'acquittal'. Consider the following examples:

- Please forgive me if I annoy you, but ...

- Would you forgive me if......(pp.188-189).

\subsection{Stating Face-Threatening Acts as a General Rule}

Here, it is implied that the $S$ does not intend to impose upon the H. Instead, circumstances force them to view FTA as an instance of some general social rule, regulation or obligations. Again, this strategy aims to distance the $\mathrm{S}$ and the $\mathrm{H}$ from the imposition by not using personal and addressing pronouns like "I" and "you" Consider the following examples: 
- Passengers will please refrain from flushing toilets on the train

instead of

- You will please refrain from flushing toilets on the train.

\subsection{Nominalizing Face-Threatening Acts}

Nominalization is one way of keeping the $\mathrm{S}$ and the $\mathrm{H}$ away from the FTAs imposition. It is explicated that "The more nouny an expression, the more removed an actor is from doing or feeling or being something; instead of the predicate being something attributed to an actor, the actor becomes an attribute of the action"(p.208). Nominalizing FTAs serve to distant the actor and adds formality to a particular situation (Watts, 2003:91). Thus, this strategy embodies a specific syntactic device that can be used to space the $S$ from the $\mathrm{H}$ as far as FTAs are concerned. However, nominalization can occur with various syntactic levels as explained by Brown and Levinson (1987):

- The subject is nominalized. Consider the following example

- The production process has quality control problems instead of Your factory is producing a lot of products that have failed with quality tests.

- The predicate is nominalized, as in:

- You performed well on the examinations and that impressed us favorably Instead of

- You performed well on the examination and that made a favorable impression on us.

- The complement is nominalized. This can be shown by

- I am surprised at your failure to reply

Instead of

- I am surprised that you failed to reply.

Accordingly, the more highly elaborate and grammatically complex utterances are, the more polite they will be. In fact, this strategy has more utilities in writing than in speech because nominalization is one feature of written discourse.

\section{Redress Other Wants of the Hearer}

Based on Brown and Levinson (1987: 209-210), this strategy is reflected in the delivery of partial compensation for the face in FTAs by redressing some particular other wants of the Hs.

\subsection{Going on record as Incurring a Debt to the Hearer}

In this strategy, the $S$ puts himself/herself in debt to the $\mathrm{H}$ due to the difficulty caused to him/her. As such, FTAs are redressed. They are further by the $S^{\prime} s$ disclaiming of any indebtedness to the $\mathrm{H}$ (Brown and Levinson, 1987:210). This can be performed by virtue of the following expression:

- I will never be able to repay you if you...

\section{Methodology}

\subsection{Description of the Test}

The test of this research subsumes hypothetical situations, all of which take place inside University border (campus, college, office, library and so on) and simulate interactions between students-professors, students-students and students-officers. Moreover, these situations focus on language learners' production of SAs in the target language rather than their comprehension of pragmatic features. These situations are formulated in a way that a kind of SD (intimate, acquaintance and distance), PRs (coercive, knowledge, rewarded, etc.) and awareness of impositions co-exist according to the English culture. Moreover, every situation subsumes background information side by side all the necessary contextual clues such as setting, participant roles and the aim of the interaction to have the required context.

\subsection{Subjects of the Test}

In the current research, 32 subjects at the Department of English, College of Education, university of Mosul were chosen to take part in the test. The test was administered on the 29th of April, 2016. The testees were given fifty minutes as time limited to answer the test situations. The time limit was set so that the testees would be more serious in giving the answers when feeling themselves under time pressure; a procedure 
that was expected to add more reliability to the subjects' responses. They were asked to carefully read these situations and write what to them to say. They were supposed to have PC and able to use language politely and appropriately because they had been exposed to literary materials as well as conversation lessons for four years. The subjects' ages ranged from 22 to 26 years. Moreover, they were informed of not writing their names as the test is directed towards pure scientific purposes.

\subsection{Data Analysis}

- It is worth noting that the subjects' responses were literally taken from their paper sheets.

- See Appendix for A complete list of situations.

\section{\# Situation one}

To save the the H's negative face, the $S$ should be maneuvering by hedging the maxim of quality so that s/he would show no commitment to the truthfulness of what is said. In this way, the $\mathrm{H}$ is given the impression not to comply and thus his/her negative face wants are appreciated. Furthermore, this implies lack of precision which confirms hesitation and uncertainty.

There has been a definite failure to respond to this situation, registering $71.825 \%$ of inappropriate responses in comparison with 28.225 being appropriate. The subjects' inappropriate responses can be explained as follows:

- Using bald-on-record strategy that threatens the $\mathrm{H}^{\prime}$ s negative face in formal contexts. An example is 'stop explaining you mistake in defining phonetics'

- Communicating a positive politeness strategy by

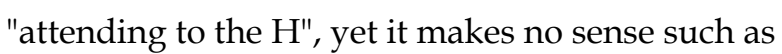
"Good Sally, although the small mistake" and "Well-good sally in spite of every little mistake that you have committed but I like your couragement and your lovely presentation."

- Failing to formulate appropriate SAs and delivered inappropriate and unrelated illocutions that indicated their poor pragmatic knowledge. Such answers are literally presented as follows: "Be careful in next time, please"; "I want to say this definition in other words and give example"; "She has to be comfortable before lecturing and prepare herself not to hesitate or feel sorry, relax before starting."

- The appropriate negative politeness strategy can be one like "hedging" and to "be conventionally indirect."

- The appropriate speech act can be one like:

"Sorry for interruption, I think there is a kind of mistake, perhaps this definition works for phonetics, as phonology is the study of the sound system of language".

"Excuse me, there might be a little mistake in this, it would be phonetics that studies the physical properties of speech sounds, I guess".

\section{\# Situation Two}

The core point in this situation lies in the letter of recommendation that comes in the form of a document where the writer assesses the recommended person's qualities, characteristics and capabilities to do a particular task (MacPherson, 2008:15). It is reported that asking a professor for such a thing can be anxietyproducing experience. From this point, the applicant behavior can be judged either as positive or negative from the referee's point of view. As such, the $S$ should employ options and indirectness towards the $\mathrm{H}$ in order not to impose upon him/her and put him/her on the spot.

The results showed that only six subjects $(18.75 \%)$ delivered appropriate responses, whereas 26 subjects $(81.25 \%)$ committed pragmatic failure as outlined in the following points:

- Going on-record with their requests that are felt to be threatening towards the H's face. Examples are "I want you to write a letter of recommendation."

- Uttering SAs with good grace, but they did not attend to the intended SAs of the context of this 
situation. Examples are: Would you help me please? I would like to complete the master's degree if you do not mind by giving me some advices"; "If you do not mind can you make a form for me I need you to write a letter for me"; ";"Please sir I have something related to my future I need your help, could you write for me a letter.

- Being incapable of producing appropriate SAs which signaled their PF and gave inappropriate answers such as "Dear Rami, I have decided to apply for postgraduated study in FFSP, what is your advice about that, can you help me please" The following three subjects started with appropriate expressions introducing "apologize", but when they moved to the focal phase they failed to provide appropriate illocutions to the request: "I am sorry to bother you but I am in need for these letters"; "I am sorry to bother you I need your help for my application." "Hello Dr. Rami, I am sorry to bother you, but I am in need for so subjects reported that they would not ask the teacher and thus no potential FTAs would occur.

- Asking the teacher and thus no potential FTAs would occur.

- The appropriate negative politeness strategy can be one like "apologizing" or "to be pessimistic".

- The appropriate speech act can be something like:

"Good afternoon Dr. Rami, I am really sorry to bother you but I wanted to ask you if you could write a little letter of recommendation for me. I promise I won't ask for another favour".

"Good afternoon Dr. Rami, I intend to apply for a postgraduate study in FFSP so I am required to complete three letters of recommendation. In fact I was wondering if you would be willing to write a letter of recommendation for me"

\section{\# Situation Three}

In this situation, representative students were not in position that gives the authority to coerce the dean's compliance in a way or another. In this context, SD is too wide that if it is represented by a hierarchical pyramid, it will be noticed that the two parties are interacting with one of them located on the top side, the dean, whereas the other on the near down base, as shown in the following figure:

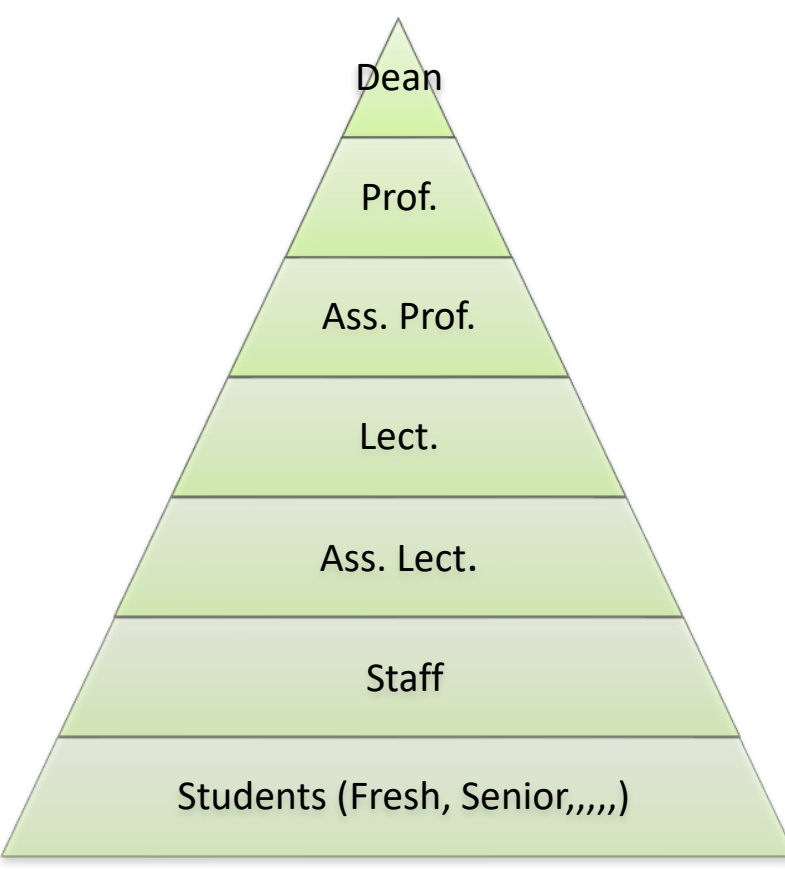

Figure (2): Pyramid Representation of the Relationships at College Level

Whereas one quarter of the subjects $(25.0 \%)$ showed a pragmatic ability and answer properly, three-quarters (75.0\%) gave inappropriate answers to this situation. How the subjects responded inappropriately is summarized as follows:

- Being unaware of the appropriate use of the professional titles. Holmes (2013:285) states that using titles with the last name (TLN) to one's superior is a further case of negative politeness. The subjects misused the appropriate title though written clearly in the situation. Furthermore, some subjects addressed the dean to get his attention without using any address form at all. Ervin-Tripp (1972 cited in Van Herk, 2012:123) calls this "no naming" that might be used as a sign of solidarity between intimates and acquaintances. For instance, a wife cannot bring herself to call her husband by his name, instead, she gets his attention by coughing or by saying "Are you listening". In fact, both cases are inappropriate to 
the context of this situation. Examples are "Mr. I think power point presentation is important in conversation lessons"; "You know there is a need to set power point presentation in our classrooms to develop students skills"; " "There is something important which we should have and which is power point ", etc. Having checked these responses, it is further noted that their illocutionary force does not convey the required meaning.

- Using direct FTAs with no redress. They definitely imposed upon the H's negative face. An example is "We need power presentation in our classrooms and you would provide this for us to develop our language".

- Committing PF in communicating requests being inappropriate and informal. An example is "Okay dean I gonna make a suggestion, we need power point equipment".

- The appropriate negative politeness strategy can be one like "showing difference" and "to be pessimistic".

- The appropriate speech act can be one like

- "Excuse me Dr. Adam, you know that technology contributes to the development of communicative skills so we do not know if there is any possibility of providing our department with data show equipment.

\section{\# Situation Four}

In this situation, the nature of presentation requires students' attendance through participating and classroom activities. Unlike passive learning, ALSs show that there is a desire that students should do it, namely to read, discuss, demonstrate, role-play and to teach others inside EFL settings (Hernades-Cantes and Blank, 2009:108). However, the degree of power relation between the presenter and the audience is somewhat close. Therefore, the $S$ would not impose on the $\mathrm{H}$ directly so as not to threaten the H's face. To avoid threatening student's negative face, the $S$ should impersonalize or nominalize his/her act so as to soften it.

It is indicated that seven subjects $(21.875 \%)$ succeeded in communicating the appropriate SAs, whereas 25 subjects $(78.125 \%)$ failed to provide appropriate SAs. An account of the inappropriate responses is presented below:

- Going bald-on-record devoid of redressive action. Examples are "If you do not participate, I'll quiz", "You have to participate or I'll make a test", "Keep sleeping, I do not care and I will continue", "Pay attention and be active."

- Using the positive politeness strategy which can be in fact appropriate to this context. Some of them used the "Joke Strategy". Examples are: "I will say a joke and tell them to make groups"; "OK students who can tell me a joke" and "By taking their attention to another subject which may be funny or saying jokes then return to the subject" The subjects appeared to elicit students' participation in a friendly way but this thing was not achieved. Other subjects endeavoured to "attend to $\mathrm{H}^{\prime \prime}$ and used in-group markers. Examples are "I would encourage them as friends not as teacher and students so that I can discover their weakness points"; " Dear students you are very clever and actually I am proud of you"; "Please pay attention we have an important topic today"; "Can an intelligent tell me what do we mean by.....?"; "Please everybody, we have an important topic, could we be communicating to each other".

- The appropriate negative politeness strategy that can be employed for such purpose can be something like "Nominalization" and "Impersonalisation".

- The appropriate speech act can be something like:

"Students, participation makes your communicative skills grow fast, it is for your advantage, please".

\section{\# Situation Five}

In this situation, three signs indicated pessimism on 
the part of the professor that he, to a great extent, would not agree to give an extension on the student's paper. He rarely gave extensions, was busy and would leave campus to do fieldwork as soon as the semester was over. Quite the opposite, the professor knew that that there was a kind of difficulty with data collection. However, the more responsible the students were to be in the class (For example, coming to class on time, participation, etc., the more likely teachers would give extension. In this way, the $S$ uses pessimistic and apologizing politeness strategies to achieve their goals.

It is detected that twenty-five subjects (78.125\%) were incapable of expressing themselves appropriately. Seven subjects $(21.875 \%)$ managed to convey appropriate SAs. The inappropriate responses can be explicated as follows:

- Far from being polite, delivering incomplete, irrelevant and inappropriate responses that show a kind of PF. Examples are "This subject is very nice"; "Excuse me could you help me with this topic", "I think this topic is interested and is important too", "Please Dr. Ahmed help me to finish this paper as soon as possible".

- Showing tendency to go on-record and consequently imposed upon H's face wants, with no choices such as "I want to have extension for this paper"; "I need your help give me extension please."

- Committing PF by using inappropriate illocutions which are further inconsistent and incomplete. An example is "I feel sorry because you are leaving our office and I will miss you I was very glad with you."

- The appropriate negative politeness strategy can be something like "to be conventionally indirect" and to "be Pessimistic."

"Excuse me Dr., Ahmed you could not give me extension on my paper, could you? You know, I found no way to gather my data so if possible I need an additional week."
"Good afternoon Dr. Ahmed, Would it be probable to have extension on my paper, there has been no possibility of collecting data, please."

\section{\# Situation Six}

In this situation, it is perfect for the representative to dictate his/her orders as rules to be carried out in relation to a formal destination. As such, the $S$ assumes that their role is solely conveying the existence of a general rule rather than imposing. This can be related to Thomas (1995:130) distinction between the interplay between the $S$ and the $\mathrm{H}$ in terms of rights and obligations. 'Rights' mean whether the $S$ is authorized to make requests and orders. 'Obligations', on the other hand, mean whether the $\mathrm{H}$ is obliged to obey these rules and orders.

However, the inappropriate responses to this situation record twenty-nine $(90.625 \%)$ of the subjects who failed to respond appropriately and politely. The other three subjects $(9.375 \%)$ answered this situation properly. To explain the subjects' inappropriate responses:

- Going on record without redressive linguistic action in conveying the request. Examples are "Students keep your uniform when you come to college. Otherwise, you will get out of it"; "All of you must wear uniform, I'll not repeat again".

- Showing pragmatic incapability of answering this situation by giving inappropriate illocutions. Examples are "I will say to make that and listen to the noticed"; " Hi everyone please pay attention there is something that all we should do"; "In order to be as one face we have to be in uniform"

- Misunderstanding the socio-cultural context of this situation and they appeared to be affected by the native culture. Examples are "my brothers and sisters, I want to tell you should wear uniform"

- Using off-record strategy by giving hints. Nonetheless, they produced what they said rather than what they wanted to say. An example is "Learning isn't by shape or wearing nice clothes, 
not difference between people only in mind".

- The appropriate negative politeness strategy can be one like "stating FTAs as a general rule".

- The appropriate speech act can be one like

"Dear students, according to the procedures and instructions of the College Council, all of you are required to be in uniform".

The following table shows in numbers and percentages the inappropriate and appropriate responses:

Table (1): Numbers and Percentages of Appropriate and Inappropriate Responses of the Total Situations

\begin{tabular}{lllll}
\hline \hline Sit. No. & $\begin{array}{l}\text { Inappropriate } \\
\text { Frequency }\end{array}$ & $\begin{array}{l}\text { Percentag } \\
\mathbf{e} \%\end{array}$ & $\begin{array}{l}\text { Appropriate } \\
\text { Frequency }\end{array}$ & $\begin{array}{l}\text { Percentage } \\
\%\end{array}$ \\
\hline $\mathbf{1}$ & 23 & 71.875 & 9 & 28.125 \\
\hline $\mathbf{2}$ & 26 & 81.25 & 6 & 18.75 \\
\hline $\mathbf{3}$ & 24 & 75.0 & 8 & 25.0 \\
\hline $\mathbf{4}$ & 25 & 78.125 & 7 & 21.875 \\
\hline $\mathbf{5}$ & 25 & 78.125 & 7 & 21.875 \\
\hline $\mathbf{6}$ & 29 & 90.625 & 3 & 9.375 \\
\hline Total & $\mathbf{2 5 . 3}$ & $\mathbf{7 9 . 1 6 6}$ & $\mathbf{6 . 6 6}$ & $\mathbf{2 0 . 8 3 3}$ \\
\hline \hline
\end{tabular}

\section{Conclusions}

Based on the analysis of data and discussion of the results, the following conclusions have been drawn upon:

- Fourth year EFL learners are pragmatically highly unaware of the H's negative face, scoring $(79.166 \%)$ of $\mathrm{PF}$, in comparison to $(20.833 \%)$ of appropriate communication. It is obvious that the percentage of failure is double compared to the percentage of success.

- A high number of learners go on record without any redressive action "direct SAs", and consequently threaten the H's negative face. This happens for a number of reasons. First, the influence of the native culture on their performance is obvious. Second, it signals that learners are unaware of the sociological variables such as SD and PRs between the $S$ and the $H$. Third; learners are unaware of politeness devices and formulas that soften the force of FTAs and save H's negative face in English.
- The subjects recorded a high degree of misunderstanding and misinterpretation of address titles. They paid no attention to the kind of appropriate titles, professional titles especially in terms of being male or female.

- It is well observed that learners, even when they communicate successfully, misuse and misconceptualize the politeness strategies appropriate use in terms of the cultural aspect of the English speech communities. Thus, the bald on record strategy is used with no redress, positive politeness and off record strategies in contexts where negative politeness would strongly be appreciated by native speakers.

- Learners' SC is somewhat exhausted. They mistakenly choose the appropriate lexical words. Their attempts to create natural expressions that look like native speakers are definitely poor. They further miscode the appropriate politeness strategies in terms of some important factors such as age, social status, gender, etc.

- It is noticed that learners transfer native language linguistic rules and cultural norms to the target language. In fact, their responses are negatively transported; a point that indicates an error in their learning.

- Learners' grammatical competence is as to some extent poor as their PC. This creates a gap between the form of language and its function.

\section{Recommendations}

In the light of the conclusions arrived at, the following recommendations have been put forward:

- English as a foreign language teachers at university level should use authentic language in explaining the scientific materials rather than simplified or over-simplified language. This might result from two reasons, namely teachers' provision of simplified input to non-native speakers so as to be well understood and teachers' 
poor competence to use language in its sociocultural context.

- More efforts should be exerted by teachers of literature to develop the strategies that work on reinforcing learners' PC. In fact, the real development of PC is embodied in the various genres of literature. Learners should be utilized to make vital roles in the classroom. For instance, learners can act socio-cultural scenes and characters as real in Drama and Novel classes. However, it is an undeniable fact that the current methods of teaching literature are too conventional and old-fashioned.

- English as a foreign language teachers should introduce pragmatic knowledge. As such, they should teach different linguistic forms and their communicative functions simultaneously. If there is mere explanation of linguistic items, learners' PC will not be cultivated.

- Learners should be provided with socio-cultural knowledge of English speaking countries where English is appropriately uttered. They should be helped to develop the appropriate uses of English in a variety of real life communicative contexts.

- There should be diversity in the content and choice of the adopted curricula in terms of real life situations context, the social rules, the cultural norms, taboos, the sort of politeness followed in these cultures, etc. besides grammatical knowledge.

\section{References}

1. Bachman, L. F. (1990). Fundamental Considerations in Language Testing. Oxford: Oxford University Press.

2. Bachman, L. and Palmer, A. (2010). Language Assessment in Practice. Oxford: Oxford University Press.

3. Brown, P. and Levinson, S. (1987). Politeness: Some Universals in Language Usage. Cambridge: Cambridge University Press.

4. Crystal, D. (2008). A Dictionary of Linguistics and Phonetics. New York: Blackwell.

5. Culpeper, J. and Demmen, J. (2012). "Nineteenth Century English Politeness: Negative Politeness, Conventional Indirect Request and the Rice of the Individual Self". In Bax, M. and Kadar, D. (eds.).
Understanding Historical Impoliteness. Amsterdam: John Benjamins, pp. 49-80.

6. Fox, K. (2004). Watching the English: The Hidden Rules of the English Behaviour. London: Hodder and Stoughton.

7. Graham, S. (1997). Effective Language Teaching. London: Multilingual Matters.

8. Hernandez-Gantes and Blank, W. (2009). Teaching English Language Learners in Career and Technical Education Programs. U.K: Routledge.

9. Kadar, D. and Haugh, M. (2013). Understanding Politeness. Cambridge: Cambridge University Press.

10. Kasper, G. and Blum-Kulka, S. (1993). Interlanguage Pragmatics. Oxford: Oxford University Press.

11. Kopytko, R. (1995). "Linguistic Politeness Strategies in Shakespeare's Plays". In Jucker, A. (ed.) Historical Pragmatics: Pragmatic Developments in the History of English. Amsterdam: Benjamins, pp. 515-540.

12. Jucker, A. H. (2008). "Politeness in the History of English". In Richard, D., Dossena, M. and Gotti, M. (eds.) English Historical Linguistics. Amsterdam: John Benjamins, pp. 3-29.

13. Leech, G. (1983). Principles of Pragmatics. London: Longman.

14. Leech, G. (2014). The Pragmatics of Politeness. Oxford: Oxford University Press.

15. Locher, A. M. (2004). Power and Politeness in Action. Berlin: Mouton de Guyor.

16. MacPherson, L. (2008). How to Write a Great Reference Letter. U.S.A: ANB Bookstore.

17. Peterwagner, R. (2005). What is the matter with Communicative Competence. Wein: Let Verlag.

18. Thomas, J. (1995). Meaning in Interaction. London. Longman.

19. Van Herk, G. (2012). What is Sociolinguistics? UK: WilleyBlackwell.

20. Watts, J. R. (2003). Politeness. Cambridge: Cambridge University Press.

21. Yule, G. (1996) Pragmatics. Oxford: Oxford University Press. 


\section{Appendix (1)}

\section{Discourse Completion Test}

\section{Gender: $\quad$ Male Female}

Age:

\section{Dear Respondents}

Would you please read the following hypothetical situations carefully, and then kindly fill in the blank in each situation with the appropriate answer you see. Be sure that your answers are for pure scientific research and not for any other purposes. Thanks in advance for being cooperative.

\section{Situation One}

At university level, students are expected to deliver weekly or monthly presentations in the classroom. Suppose that Sally, your classmate, has an evening seminar on the relationship between phonetics and phonology. She mistakes by defining phonology as the study of the physical properties of speech sounds (this happens because she mostly feels hesitant and nervous; she is not used to be in front of students before. Bear in mind that you and the presenter are acquaintances and the role of the teacher in this session is just as a guide). You decide to correct her mistake as this definition works for phonetics. You say

\section{Situation Two}

As you are about to graduate, you intend to apply for a postgraduate study in Fulbright Foreign Students Program (FFSP). This program nominates qualified students as candidates to complete the Master's degree at one of the American universities. One of the prerequisites of this program is that applicants should be recommended by a teacher who has been teaching the applicant for one year at least. However, three letters of reference are required to complete your application. You decide to ask your teachers to write these letters. First, it is 1:30 p.m. and you choose to go to Dr. Rami's office and ask him for a letter of recommendation. You say

\section{Situation Three}

In a scheduled meeting held by the College Council to discuss the main difficulties and needs students face. The dean, Dr. Sameer Adam, held a meeting with the representatives of each department to investigate students' needs. Suppose that you are one of them representing English department and try to notify the dean that your department classrooms lack to power point presentation equipment "Data Show" as being valuable and useful in conversation lessons. You say......

\section{Situation Four}

Imagine that your teacher Dr. Hani has assigned you to provide a session on active learning strategies in EFL classes. Accordingly, such a topic hypothesizes a dynamic attendance of the students. It is 8:30 a.m., the first session, and you begin to explain what ALSs are, and how they can be invested. You see that most of the students are inactive and show no enthusiasm to interact. If you want to urge them to participate actively, you would say

\section{Situation Five}

You have been assigned to write a term paper of a course in your major, yet the paper has not been finished. You intend to ask your professor Dr. Ahmed for an extension as much difficulty has been faced in collecting the required data. In fact, Prof. Ahmed realizes the problem you have been experiencing with data 
collection. You are aware that he rarely extends the time limits of term papers as he is always keeps busy and immediately on the completion of the semester he leaves the campus so as to do field work. However, you think you may succeed in getting extension as the papers focuses on a topic of interest to him. It is 2:00 p.m. and you are in his office now. You would say

\section{Situation Six}

Suppose that you are representing the Students' Union at your college. So you are in charge of students' interests and the management of their affairs. You have been notified by the College Council that all students should be in uniform you are now in the class. You say..... 